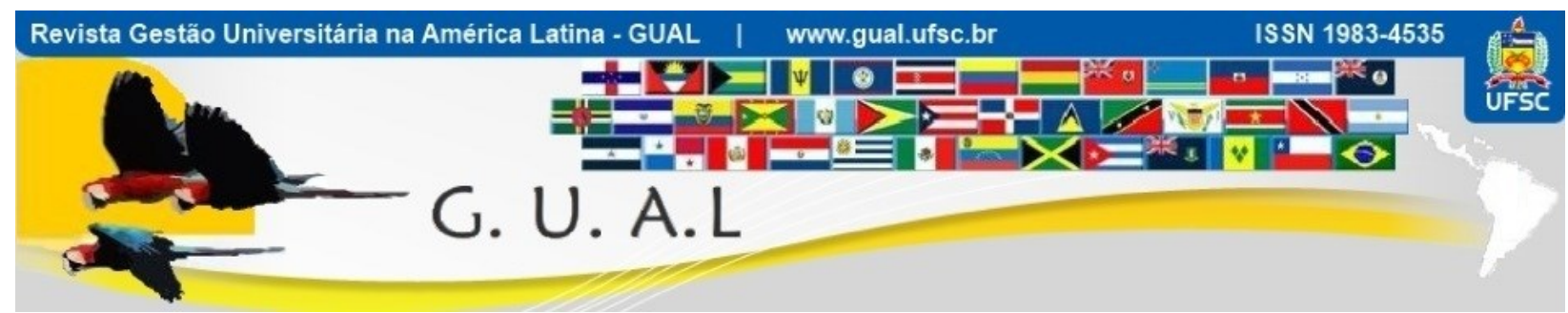

DOI: http://dx.doi.org/10.5007/1983-4535.2014v9n4p274

\title{
MOBILIDADE DE DOUTORANDOS PARA O SANDUÍCHE: INTERNACIONALIZAÇÃO DA IES OU DO DOUTORANDO?
}

\author{
MOBILITY OF PHD STUDENTS IN SANDWICH: INTERNALIZATION OF THE \\ INSTITUTION OR OF THE STUDENT?
}

Adriana Amadeu Garcia Torres, Doutoranda

Universidade do Grande Rio - UNIGRANRIO adriana.amadeu.garcia@gmail.com

Claudio Marcos Maciel da Silva, Doutorando Universidade Estácio de Sá professorclaudiomaciel@gmail.com

Josir Simeone Gomes, Doutor Universidade do Grande Rio - UNIGRANRIO josirsgomes@gmail.com

Recebido em 04/dezembro/2015

Aprovado em 14/outubro/2016

Sistema de Avaliação: Double Blind Review

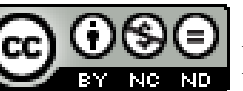

Esta obra está sob uma Licença Creative Commons Atribuição-Uso. 


\title{
RESUMO
}

É objetivo deste artigo verificar se a mobilidade de doutorandos para o sanduíche, da maneira como tem sido aplicada, pode representar a internaciolização da IES ou seria somente uma experiência particular do doutorando. Para tanto, o primeiro passo foi a pesquisa bibliográfica acerca do tema internacionalização de IES e das regras para o doutorado sanduíche. A pesquisa foi qualitativa e o instrumento de coleta de dados um roteiro de entrevista semiestruturada com questões abertas aplicado junto a sete doutorandos, contemplando todo o processo de mobilidade do estudante: desde o planejamento, incluindo a operacionalização, o financiamento, a execução e a finalização e controle do processo. Para o tratamento de dados, adotou-se a análise do conteúdo com o auxílio do software de análise qualitativa Atlas TI versão 6.0. Considerando todas as etapas do processo de mobilidade do doutorando, foi possível tratar três momentos: etapas anteriores ao sanduíche, o sanduíche e o retorno do sanduíche. Em suma, apesar do doutorado-sanduíche ser um programa de mobilidade de pessoas que deveria representar um processo de internacionalização da IES, precisa de ajustes, pois o processo se mostra eficiente somente para o estudante.

Palavras-chave: Internacionalização. Mobilidade de Pessoas. Educação Superior.

\begin{abstract}
The aim of this article is to check if the mobility of $\mathrm{PhD}$ students in sandwich, in way it has been applied, represents the internationalization of the Institution or a particular experience of the $\mathrm{PhD}$ student. First of all, the bibliographic research about internationalization of higher education and the rules for $\mathrm{PhD}$ sandwich was done. It's a qualitative research that uses a semi-structured script with open questions for make interviews with seven $\mathrm{PhD}$ students. This instrument contemplating the whole process of mobility: from planning, operationalization, financing, execution and finalization and control. For the data treatment, the content analysis was adopted with the aid of the qualitative analysis software Atlas TI version 6.0. With the results it is possible to considering the process of $\mathrm{PhD}$ student's mobility in three different moments: steps prior to the sandwich, the sandwich and the return of the sandwich. Finaly, the conclusion is, although the $\mathrm{PhD}$ sandwich is a program of mobility of persons that should represented the internationalization of Institution, it is need adjustments, because the process, as it has been applied, is efficient only for the student.
\end{abstract}

Key words: Internationalization. Mobility of persons. Higher Education. 


\section{INTRODUÇÃO}

A globalização, marca a "interdependência crescente entre as várias regiões do mundo resultante do rápido aumento do fluxo de bens, serviços, capital, pessoas e informação" (LAUS, 2012, p. 44), o que traz complexidade para o processo de gestão, ao mesmo tempo em que apresenta a internacionalização como alternativa para as organizações. Por outro lado, diante desse contexto globalizado, a qualificação do trabalhador e o desenvolvimento de novos produtos e tecnologias delegam à educação a responsabilidade do crescimento econômico da nação. (ALMEIDA, 2014, p. 494).

Desta forma, considerando a educação via Instituições de Ensino Superior (IES), Altbach e Knight (2007) afirmam que, enquanto a globalização é um acontecimento inalterável, a internacionalização envolve muitas escolhas relacionadas ao entendimento mútuo de padrões de qualidade e credibilidade das IE construído ao longo de anos.

Para fins de internacionalização as IES têm como alternativas: mobilidade de estudantes e/ou docentes que vão para o exterior; mobilidade de programas, onde cursos são ministrados fora do país; e mobilidade de instituições, quando há abertura de unidades no exterior. (KNIGHT, 2003). E, especialmente considerando a mobilidade de pessoas, este não é um fenômeno recente.

A internacionalização de IES via mobilidade de estudantes, provém da colonização (1500-1822) quando "a classe dominante formava-se na Europa e as concepções educacionais impostas vinham de ordens jesuíticas além-mar" (SAVIANI, 2007). No entanto, somente a partir dos anos 90, políticas sistematizadas de fortalecimento dos projetos educacionais da década de 80 começaram a ser adotadas.

Neste contexto, as estratégias para internacionalizar as IES brasileiras ganharam incrementos significativos via programas federais de fortalecimentos da mobilidade acadêmica, de modo que, já em 2010, eram mais de três milhões de estudantes estudando fora de seus país de origem. (REDDEN, 2010).

Dentre os programas implementados, tem-se o Programa de Doutorado Sanduíche no Exterior (PDSE), instituído em 2011, para substituir o Doutorado Sanduíche Balcão e o Programa de Doutorado no País com Estágio no Exterior (PDEE), com o intuito de ampliar o número de cotas concedidas as IES e agilizar o processo de implementação das bolsas de estágio de doutorando no exterior (CAPES, 2015a). 
Diante do exposto, é notório o estímulo à mobilidade de pessoas nas IES brasileiras, porém, é necessário resgatar o propósito desse processo, que seria de: “apoiar a formação de recursos humanos de alto nível por meio da concessão de cotas de bolsas de doutorado sanduíche no exterior às Instituições de Ensino Superior com cursos de Doutorado reconhecidos pela Capes" (CAPES, 2015a).

Portanto, trata-se de um auxílio financeiro para a formação do doutorando, o que tende a estimular sua mobilidade em favor da IES na qual está vinculado. Logo, esta seria uma forma de internacionalizar a IES, mas a práxis gera questionamentos quanto ao propósito de tal iniciativa. Isto, pois, ainda que a mobilidade de pessoas seja uma forma de internacionalização, não se trata de simplesmente enviar o discente ou docente para o exterior, não é tão simples assim.

Somado ao exposto, tem-se dados objetivos que demonstram existir um número expressivo de vagas não preenchidas (CAPES, 2015a), ainda que se tenha demanda para tais programas; além da suspeita de assimetria de informação e da constatação de que áreas, como Administração, não são contempladas por programas, como, por exemplo, o PDSE, que faz parte do Programa Ciência sem Fronteiras - CsF, instituído pelo Decreto Lei no 7.642/11 (CAPES, 2015c), que recebeu destaque no país. (ALMEIDA, 2014, p. 495).

Ademais, está se considerando a internacionalização, que, como exposto, se apresenta como uma opção para a organização e passou a ser entendida como um ativo econômico e atuar como fator de desestabilização do equilíbrio econômico dos países ou regiões envolvidas (LAUS, 2012, p. 60); logo, é fundamental compreender as nuances deste processo de múltiplas escolhas, considerando os personagens centrais que o compõe: IES e estudantes.

A questão a ser respondida é: a mobilidade de doutorandos para o sanduíche representa a internaciolização da IES ou do doutorando? O objetivo é verificar se a mobilidade de doutorandos para o sanduíche, da maneira como tem sido aplicada, pode representar a internaciolização da IES ou seria somente uma experiência particular do doutorando.

\section{A GLOBALIZAÇÃO E A INTERNACIONALIZAÇÃO DAS IES}

A fim de melhor compreender a globalização, vale destacar que o termo provém das escolas de negócio dos Estados Unidos, no início da década de 80 e ganhou espaço com viés 
da imprensa econômica e financeira, predominantemente de língua inglesa, não tendo demorado para chegar ao discurso político neoliberal. (SILVA, 2013, p. 20).

Aliás, a mundialização do capital é a que corresponde ao termo inglês "globalização", que traduz a capacidade estratégica de todo grande grupo oligopolista, voltado para a produção manufatureira ou para as principais atividades de serviço, ao adotar por conta própria, um enfoque e condutas “globais". (CHESNAIS, 1996, p. 16).

Em relação ao impacto da globalização, o mesmo pode não ser tão evidente na prática, mas é inalterável, conforme exposto, na medida em que...

formam-se estruturas de poder econômico, político, social e cultural, internacionais, mundiais ou globais descentradas, sem qualquer localização nítida neste ou naquele lugar, região ou nação [...] parecendo flutuar sobre Estados e fronteiras, moedas e línguas, grupos, classes, movimentos sociais e partidos políticos. (IANNI, 1992, p. 93).

Com a globalização as fronteiras deixam de estar nítidas, "o saber passa a ser despersonalizado, desterritorializado e globalizado" (BRETON, 2003, p. 26). O mesmo vale para as noções de tempo e espaço. No entanto os impactos são globais, pois, as redes de articulações e as alianças estratégicas "constituem e desenvolvem tecidos que agilizam relações, processos e estruturas, espaços e tempos, geografias e histórias" (IANNI, 2002, p. 249).

Somado ao exposto, o desenvolvimento dos transportes, na perspectiva de diferentes modais ou das tecnologias da informação, internet etc. aceleraram a internacionalização de diversas instituições, entre elas, as de ensino superior, tornando este elemento a face mais visível da globalização (CHESNAIS, 1996). E, "as permanentes oscilações da sociedade global se constituem em campo fértil para reflexões centradas em questões de caráter histórico, social, ideológico e epistemológico" (SILVA, 2013, p. 19).

Em suma, trata-se da transição da rigidez para uma nova base produtiva de acumulação 'flexível' (HARVEY, 2010, p.119), ou seja, o acesso ao conhecimento científico e técnico, apresenta uma renovação de interesse e de ênfase, na medida em que o conhecimento da última técnica, do mais novo produto, da mais recente descoberta científica, implica a possibilidade de alcançar uma importante vantagem competitiva. E "o saber se torna mercadoria-chave, a ser reproduzida e vendida a quem pagar mais" (HARVEY, 2009, p. 151).

Por outro lado, a internacionalização do Ensino Superior no Brasil consiste em um fenômeno com contornos próprios e complexos ainda que, no campo da gestão pública, este 
tema muitas vezes se reduza a apresentação de quantitativos dos investimentos feitos e dos alunos contemplados. (ALMEIDA, 2014, p. 495).

Este pode ser algo contínuo, como um processo sinérgico e transformador, envolvendo os currículos e a pesquisa, influenciando as atividades de estudantes, professores, administradores, e toda comunidade em sentido amplo (BARTELL, 2003). Assim, ...

corresponde ao processo de diálogo (trabalhos conjuntos, cooperação, intercâmbio, conflitos e problemas surgidos) com outras universidades ou organizações variadas (empresas, governos, agências internacionais, ONGs) do mundo exterior à fronteira nacional na concepção, desenvolvimento ou implementação de suas funções de ensino, pesquisa e extensão. (LAUS, 2012, p. 81).

O Plano Nacional de Educação (PNE- Lei 13.005/2014) é o documento mais atual no país para impulsionar o processo de internacionalização para os próximos dez anos e dentre as 20 metas propostas, três são destinadas ao nível superior.

Meta 12.12) Consolidar e ampliar programas e ações de incentivo à mobilidade estudantil e docentes em cursos de graduação e pós-graduação, em âmbito nacional e internacional, tendo em vista o enriquecimento da formação de nível superior.

$[\ldots]$

Meta 13.7) Fomentar a formação de consórcios entre IES públicas, com vistas a potencializar a atuação regional, inclusive por meio de plano de desenvolvimento institucional integrado, assegurando maior visibilidade nacional e internacional às atividades de ensino, pesquisa e extensão.

$[\ldots]$

Meta 14.9) Consolidar programas, projetos e ações que objetivem a internacionalização da pesquisa e da pós-graduação brasileiras, incentivando a atuação em rede e o fortalecimento de grupos de pesquisa. (PNE, 2014).

O Programa de Doutorado Sanduíche no Exterior (PDSE) é uma das iniciativas que atende a tal propósito ofertando bolsas para doutorandos realizarem cursos em instituição no exterior, retornando ao Brasil para a integralização de créditos e defesa de tese. Ainda que não contemple todas as áreas, seu manual de candidatura (CAPES, 2015b) evidencia alguns procedimentos que auxiliam na compreensão das exigências para a mobilidade de doutorandos na modalidade sanduíche, conforme será apresentado a seguir.

\subsection{MOBILIDADE DE DOUTORANDOS VIA MODALIDADE SANDUÍCHE}

Antes de tratar da mobilidade de doutorandos de forma específica, vale esclarecer o propósito de tal processo, na medida em que representa uma das formas mais presentes de 
internacionalização da educação superior. A mobilidade de estudantes, assim como a de cursos, "requer o deslocamento para o consumo do serviço em lugar onde será ofertado temporariamente" (KNIGHT, 2006, p. 30).

As vantagens são: distribuição de conhecimento e tecnologia mundiais, padronização de critérios de qualidade, e transferência de ideias complementares para países embarcando em novos projetos políticos, econômicos e sociais (MURPHY, 2007), no entanto o custo é alto.

Assim, no âmbito interno, a internacionalização de uma universidade propõe-se à melhoria da qualidade, da pertinência e eficácia e no âmbito externo, a promover seu potencial de ensino e pesquisa, que em última instância é um fator fundamental para a instituição ser admitida nas redes internacionais formais e/ou informais de educação superior. (SEBASTIÁN, 2004, p. 16).

As regras para adesão aos programas de doutorado sanduíche destacam que o estudante deve estar "formalmente matriculado em curso de doutorado no país e comprovar qualificação para usufruir, no exterior, da oportunidade de aprofundamento teórico, coleta e/ou tratamento de dados ou desenvolvimento parcial da parte experimental de sua tese a ser defendida no Brasil" (CAPES, 2015c).

A qualificação mencionada se refere ao fato de que, para ser elegível, o estudante não pode estar aposentado, precisa conhecer o idioma utilizado pela instituição de destino, ter anuência do coordenador do curso e orientadores de ambos os países e seu projeto deve estar enquadrado nas áreas contempladas pelo Programa.

Portanto, o perfil buscado para participar da modalidade sanduíche é delimitado de modo a atrair "recursos humanos de alto nível" (CAPES, 2015c), apoiando sua formação por meio da concessão de bolsas com o propósito de contribuir para o estabelecimento e/ou manutenção do intercâmbio científico dos programas de pós-graduação do país com seus congêneres no exterior, como consta no Manual de Candidatura.

Todavia, ainda que se tenha grande estímulo para a mobilidade de pessoas nas IES, "ao tentar suprir lacunas deixadas desde os primórdios da história educacional a qualidade do ensino passa a um segundo plano" (ALMEIDA, 2014, p. 504). Somado ao exposto, o volumoso financiamento governamental pode estar atraindo IES para o processos de internacionalização. Situação esta que pode não ser sustentável no longo prazo e pode estar desvirtuando a proposta original do programa. 
Além disso, as políticas de internacionalização da educação superior no país esbarram constantemente em problemas oriundos da concepção histórica de educação elitista, como por exemplo a barreira da língua estrangeira. E, não só as bases das políticas linguísticas continuam as mesmas, como os investimentos na formação de professores de línguas estrangeiras são insignificantes e há pouca valorização da aprendizagem de idiomas nas escolas da rede básica de ensino, levando a restrições futuras de programas para o nível superior. (ALMEIDA, 2014, p. 502).

De qualquer forma "não existe uma maneira certa ou única para internacionalizar, [...] esta é um meio para a melhoria ampla do ensino superior entendido como gerador de conhecimento novo [...] e principalmente de valores e de cidadania e não como um fim em si mesmo". (LAUS, 2012, p. 23-24). Para tanto, "tal processo deve ser parte integral dos planos de desenvolvimento, planejamento estratégico e políticas gerais das instituições de educação superior" (GACEL-ÁVILA, 1999, p. 38).

Ainda que os autores defendam que a internacionalização é da IES, não se pode desconsiderar o fator humano envolvido neste processo, conhecido como capital de mobilidade. Os elementos principais que o compõe são: a família e sua história pessoal; experiência anterior de mobilidade e competência linguística; capacidade de "adaptação" a outra cultura; e sua personalidade. Inclusive, destaca-se que quanto maior a oportunidade de mobilidade mais acesso aos recursos, assim como inverso pode ser verdadeiro (MURPHY LEJEUNE, 2002, p. 51), ou seja, caso o estudante domine outros idiomas, por exemplo, ele pode ter mais chances com a mobilidade internacional.

Resultados de estudos demonstram que, as motivações que determinam a decisão de estudantes internacionais em investirem em programas de intercâmbio em instituições de educação superior no Brasil são: "interesse em conhecer o país, aprender o idioma, ter um diferencial no currículo e investir em uma carreira internacional" (SILVA, 2013, p. 141). E, não por acaso, a mobilidade de estudantes vem sendo apontada como o fator mais importante no processo de internacionalização da educação superior, inspiradora das políticas e práticas, tanto no nível nacional como no institucional, no que se refere à certificação de qualidade, credenciamento bem como aos aspectos acadêmicos, curriculares e culturais (DE WIT, 2008 p. 1). 


\section{METODOLOGIA}

O primeiro passo para este estudo foi a pesquisa bibliográfica acerca do tema internacionalização de IES e das regras para o doutorado sanduíche, de modo que fosse possível partir para a pesquisa de campo com forte embasamento teórico, tornando possível a adoção da Grounded theory (STRAUSS; CORBIN, 1990), na medida em que o propósito era identificar as informações no ambiente não partindo de qualquer hipótese $a$ priori.

A seleção dos sujeitos foi de forma aleatória de modo que a amostra fosse composta por doutorandos que tivessem até cinco anos de conclusão do programa de doutorado no ato da entrevista, que ocorreu entre os dias 10 e 30 de julho de 2015. A escolha por este grupo se deve ao fato de estarem envolvidos com esta modalidade de doutorado (doutorado-sanduíche) e com informações atuais, todas compreendidas nos últimos dez anos.

Buscou-se diversificar as IES atuantes, ainda que tenha restringido o estudo ao Rio de Janeiro, em função do quesito acessibilidade. A mesma preocupação foi tida com os países em que o sanduíche foi realizado, buscando experiências distintas que agregassem valor a pesquisa (vide Quadro 1). Ainda assim, vale destacar que não será realizada qualquer tipo de comparação, considerando a categoria administrativa (público ou privada), segmentação (público alvo de rendas mais altas ou mais populares) e/ou modelo de gestão (familiar, burocrática ou corporativa), visto que não foi esta a proposta e que a diversidade dos entrevistados auxiliou o alcance do objetivo de identificar elementos em comum que pudessem levar a resposta da questão de pesquisa: 'quem' se internacionaliza?

\begin{tabular}{|c|c|c|c|c|c|}
\hline Entrevistado & Gênero & Faixa Etária & Estado Civil & Área & País do sanduíche \\
\hline \hline A & Masculino & 25 a 35 anos & Solteiro & Humanas & França \\
\hline B & Masculino & 35 a 45 anos & Solteiro & Humanas & Haiti \\
\hline C & Masculino & 25 a 35 anos & Solteiro & Saúde & Estados Unidos \\
\hline D & Masculino & 25 a 35 anos & Solteiro & Humanas & Estados Unidos \\
\hline E & Feminino & 35 a 45 anos & Casado & Saúde & Alemanha \\
\hline F & Feminino & 25 a 35 anos & Solteiro & Saúde & Estados Unidos \\
\hline G & Masculino & 25 a 35 anos & Casado & Saúde & Estados Unidos \\
\hline
\end{tabular}

Quadro 1 Perfil da amostra.

A entrevista foi semi-estruturada junto a sete doutorandos, com base em um roteiro inicial que contemplava todo o processo de mobilidade do estudante: desde o planejamento, incluindo a operacionalização, o financiamento, a execução e a finalização e controle do processo. 
Todas as perguntas eram abertas e, ainda assim, novas perguntas poderiam ser realizadas de acordo com o decorrer da entrevista, chegando ao roteiro final apresentado na Quadro 2. Desta forma, as entrevistas duraram cerca de uma hora e foram gravadas e transcritas de forma a facilitar a fase de organização dos dados coletados.

\begin{tabular}{|c|l|}
\hline & $\begin{array}{l}\text { IES em que cursa o doutorado } \\
\text { Ano de inicio do curso } \\
\text { Área do doutorado } \\
\text { Faixa etária } \\
\text { Estado civil } \\
\text { Filhos } \\
\text { Experiência profissional }\end{array}$ \\
\hline 1) no seu projeto de pesquisa antes de ingressar no programa de doutorado já previa o período de \\
estudo no exterior?
\end{tabular}

Quadro 2 Instrumento de coleta de dados. (versão final).

Os protocolos foram seguidos de forma a obter uma maior confiabilidade na pesquisa, dentre os quais o piloto, onde o roteiro da entrevista, elaborado com base nas referências bibliográficas foi utilizado em uma entrevista com um doutorando que viveu a experiência do programa de doutorado sanduíche, de forma a verificar se as perguntas contidas eram de fácil 
compreensão por parte do entrevistado. Nesta oportunidade, foram identificados outros pontos que deveriam constar no roteiro inicial, tendo sido os mesmos inclusos na versão final do instrumento de coleta de dados.

Após a realização de cada entrevistas, seu conteúdo era organizado e analisado de forma a identificar algum item que pudesse enriquecer o roteiro de entrevista posterior. Procedimento este que reforçou a validação da pesquisa. O roteiro de entrevista e o relatório final foram submetidos para avaliação e aprovação de um pesquisador Bolsista de Produtividade nível 2 - CNPq.

Para o tratamento de dados, o método utilizado foi a análise do conteúdo. Inicialmente foram estipulados códigos de forma a ajudar na identificação de trechos das entrevistas realizadas que abordem o tema em questão. Em seguida, novos códigos foram identificados no decorrer da análise das entrevistas e consolidados nas etapas do programa do doutorado sanduíche. Assim, todos os códigos foram agrupados em famílias onde constavam as etapas do programa do doutorado sanduíche: planejamento, operacionalização, financiamento, execução e finalização e controle. E para facilitar a organização e apresentação das informações coletadas foi utilizado o software de análise qualitativa Atlas TI versão 6.0.

\section{ANÁLISE DOS RESULTADOS}

Considerando todas as etapas do processo de mobilidade do doutorando, foi possível tratar três momentos: etapas anteriores ao sanduíche, o sanduíche e o retorno do sanduíche, de modo que o processo pôde ser analisado de forma detalhada a fim de identificar 'quem' realmente está sendo internacionalizado: IES ou doutorando?

\subsection{ETAPAS ANTERIORES AO SANDUÍCHE}

Grande parte dos entrevistados optou por conta própria realizar parte de seu programa de doutorado no exterior. O papel do orientador, nesta fase de planejamento do programa, foi a de intermediar um professor de contato no exterior, de forma a viabilizar a carta de aceite de uma Instituição de Ensino ou Centro de Pesquisa.

A Instituição de Ensino local foi pouco citada pelos entrevistados como parte ativa nesta fase de articulação entre a IES no exterior e o órgão financiador. Cabe destaque para a questão da documentação necessária, especialmente nos países que tem a língua estrangeira 
como predominante, pois a tradução juramentada se mostrou dispendiosa e é de responsabilidade do doutorando.

Todos os documentos tem que ser juramentados em francês. Parece pouco, mas demanda muito tempo, pois existem poucos tradutores juramentados aqui no Rio, e em média demoram cerca de três meses para realizar a tradução. (Entrevistado A - Humanas).

As certidões, cartas de recomendação, histórico acadêmico, tudo juramentado [...] foi gasto um enorme dinheiro com isto. (Entrevistado $\mathrm{C}-$ Humanas).

Para países que exigem visto para estudante, o custo deste também é de responsabilidade do doutorando e, em alguns casos, tem um valor consideravelmente alto.

Existem um conjunto de taxas, em torno de 500/600 dolares, que precisava custear para este tipo de visto [...] Entretanto a entrevista em inglês foi muito rápido. (Entrevistado D - Saude).

Não por acaso, organização foi uma das palavras mais citadas pelos entrevistados quanto a consolidação dos documentos necessários para a solicitação de financiamento para efetivação de parte do programa de Doutorado no exterior, na modalidade sanduíche.

Por outro lado, uma vez aprovada a concessão das bolsas, nenhum dos entrevistados verificou qualquer problema relativo a atrasos no repasse da bolsa de estudos. Pelo contrário, foi mencionado que o Banco do Brasil dispõe de uma estrutura eficiente junto as suas sucursais no exterior de modo a servir de intermediador deste repasse.

Outro termo bastante citado pelos doutorandos foi a de necessidade de um planejamento detalhado sobre as atividades de pesquisa a serem desenvolvidas durante o doutorado sanduíche. Muitos afirmam que a ausência deste planejamento pode reduzir a importância do período de estudo no exterior, levando o mesmo a uma mera viagem de turismo.

Cabe destacar a forma como alguns alunos de doutorado se portam lá fora. No meu caso, havia uma aluna anterior que deixou uma péssima imagem do Brasil. Isso fez com que a minha orientadora externa titubeasse em me aceitar. Esta aluna anterior trabalhou muito pouco, se ausentava muito do laboratório [...] e isso fez com que ficasse com uma imagem negativa do Brasil. (Entrevistado E - Saude) 


\subsection{O SANDUÍCHE}

Todos os doutorandos entrevistados afirmaram que o principal pré-requisito para a execução do período de estudo no exterior é possuir um projeto de pesquisa já qualificado pela IES. Premissa esta coerente com o formato de organização dos programas de pós graduação stricto sensu que prevê, na maioria das vezes, a aprovação do projeto de tese ao final das disciplinas cursadas.

Desta forma, os doutorandos não tiveram a obrigatoriedade de cursar uma disciplina de forma a completar os créditos de seus respectivos programas. No entanto, alguns cursaram disciplinas como ouvintes e não perceberam diferença na qualidade dos estudantes estrangeiros, mas sim no protocolo das aulas que são mais pontuais e valorizam o fato de estarem ali presentes cursando uma disciplina em uma instituição de renome.

O que me impressionou foi que a aula começava no horário e terminava no horário. Além disto, os alunos participam de palestras e eventos com gosto, e não apenas para cumprir uma obrigação imposta pelo programa. (Entrevistado F - Saúde)

Os alunos chegam na sala de aula no horário e saem no horário. (Entrevistado C - Humanas)

Destaca-se também, principalmente para os entrevistados na área de Saúde, a diferença considerável entre os recursos disponíveis para a realização de pesquisas em laboratório. A descentralização dos recursos de pesquisa é paradoxalmente mais eficiente e mais controlada do que no Brasil.

Você tem acesso de um dia para o outro. Dentro da Universidade tinha um prédio que era só atravessar a rua que tinha tudo que é reagente, equipamentos. Simplesmente falava quero isso, quero aquilo, e com um número de uma conta pessoal, que era de pesquisa, era requisitado, dai voltava ao laboratório. (Entrevistado D - Saúde)

Quanto aos doutorandos na área de humanas, os mesmos relataram o diferencial em estudar no exterior, a experiência de ter contato direto com autores cujos artigos foram estudados no Brasil, bem como a facilidade em coletar dados para a pesquisa.

Por exemplo quero um livro. Voce chega na biblioteca e passa a palavrachave para o bibliotecário, ele faz de tudo para tentar te ajudar. Porém é uma faculdade privada, dispõe de mais recursos. (Entrevistado C - Humanas) 
A visão de ciência também é discutida. Existe um alto grau de endogenia aqui no Brasil, utilizando muito pouco contato com pesquisadores de outros países. Isto foi detectado tanto em relatos na área de saúde como na área de humanas.

No Brasil, muitos grupos de pesquisa fazem repetição de experimentos que na verdade são muito mais do mesmo. Eu estudo o comportamento do caranguejo A em relação a substância. Outra pesquisa é a reação do caranguejo B em relação a mesma substância. (Entrevistado D - Saúde )

A relação com o orientador externo variou de entrevistado para entrevistado. Enquanto alguns relataram que o contato era muito próximo, outros lamentaram não terem tido uma experiência direta com o orientador externo, mas sim com sua equipe. Porém isto não comprometeu o desenvolvimento da pesquisa em sua fase no exterior.

Em relação aos contatos com os orientadores do país de origem, os mesmos foram realizados com maior regularidade, em muitas das vezes facilitados por conferências através do Skype. Nestes encontros, os avanços encontrados nesta fase da pesquisa eram compartilhados com os seus orientadores.

Nenhum dos doutorandos relatou ter sofrido qualquer tipo de preconceito ou discriminação pelo fato de serem brasileiros em outro país. Todos, sem exceção, elogiaram o acolhimento e contato estabelecido, tanto com professores, como também os demais alunos conhecidos durante a estadia no exterior.

\subsection{RETORNO DO SANDUÍCHE}

No período de retorno ao país de origem, os dados coletados e as pesquisas realizadas ajudaram não só o desenvolvimento da tese, bem como, para alguns entrevistados, o início de elaboração de seus projetos para o pós-doutorado. Uma vez já articulado uma rede considerável de contatos acadêmicos, ficou mais fácil a elaboração de uma proposta visando a entrada em um programa de pós-doc.

Ainda assim, os doutorandos concluíram seus trabalhos com uma certa frustração, pois nenhum dos seus professores orientadores no exterior fez parte da banca de defesa do doutorado. Assim, justamente aqueles que os acolheram e os orientaram durante o tempo do doutoramento sanduíche, não puderam estar presentes no momento mais importante de seu programa de doutorado: a defesa da tese.

No que tange a validade desta experiência no exterior, destaca-se o salto qualitativo na produção científica dos entrevistados que realizaram o doutorado-sanduíche. Ao verificar o 
curriculum lattes deles, foi constatado um salto significativo de qualidade em suas publicações acadêmicas, realizadas em grande parte via periódicos internacionais de grande impacto.

Modificou a minha forma de escrever, de pensar a ciência. Esta experiência facilitou o acesso ao pós-doutorado e também para a viabilização de vários concursos que fiz. Também se traduziu em produção científica. (Entrevistado G - Saúde)

Em relação a prestação de contas, apenas um doutor relatou que teve problemas com o seu órgão financiador deste programa no exterior. A solicitação exagerada de prestação de contas passa a ter uma postura mais intimidadora do que orientadora quantos aos gastos realizados.

\section{CONSIDERAÇÕES FINAIS}

Com o objetivo de verificar se a mobilidade de doutorandos para o sanduíche, da maneira como tem sido aplicada, pode representar a internaciolização da IES ou seria somente uma experiência particular do doutorando, o presente trabalho traz informações que tratam todo o processo de sanduíche separado em três momentos: etapas anteriores ao sanduíche, o sanduíche e o retorno do sanduíche.

Desta forma, foi possível identificar aspectos interessantes em cada momento. Com relação a primeira etapa, que antecede o sanduíche, está claro que o engajamento atualmente é do estudante, assim como o custeio deste processo. Inclusive esta parece ser uma das entraves para a adesão de estudantes ao programa, onde o único auxílio do orientador se dá com o contato estabelecido com o orientador e/ou IES externos.

Durante o sanduíche a necessidade de um planejamento ficou evidente, na medida em que não há obrigatoriedades sequer de cursar disciplinas, visto que as mesmas já foram concluídas no país de origem. Inclusive, quase todos os doutores entrevistados afirmaram que existe uma forte possibilidade deste programa se transformar em uma viagem de turismo, caso este planejamento não tenha sido realizado minunciosamente.

Por outro lado, o contato com o orientador de renome no exterior para o desenvolvimento da tese, embora sirva de referência para a aprovação do doutoradosanduíche, via cartas de aceites, na prática, via de regra, torna a relação com o orientando distante, mesmo estando o orientando próximo fisicamente. 
Por fim, no retorno do sanduíche, os doutorandos são unânimes ao informar seus saltos qualitativos, também presente em números em seus currículos lattes. Especialmente os doutorandos que optaram por assistir disciplinas como ouvintes, estes gozaram de um processo intenso de aprendizagem e aprimoramento profissional.

Em suma, apesar do doutorado-sanduíche ser um programa de mobilidade de pessoas que deveria representar um processo de internacionalização da IES, precisa de ajustes, pois o processo se mostra eficiente, mas não para cumprir seu propósito, mas sim do estudante.

O motivo para o desvio da função do Programa é ausência de estratégias das IES em incentivar sua prática vinculando-os a seus projetos de pesquisa. Assim, estas acabam por ser 'usadas' por estudantes que buscam sua própria internacionalização. Cenário este que comprova a insustentabilidade deste programa no longo prazo, pois tem atraído IES em função dos altos investimentos realizados, mas sem um plano efetivo.

Para sugestões de pesquisas futuras seria importante o acompanhamento profissional e acadêmico dos doutores que realizaram o doutorado-sanduíche, de forma a perceber a contribuição que o programa de estudo no exterior gera uma externalidade positiva para a comunidade científica no Brasil.

\section{REFERÊNCIAS BIBLIOGRÁFICAS}

ALMEIDA, S. M. C. A internacionalização da educação superior e suas muitas fronteiras. Jornada do Histedbr, Caxias, v. 12, pp. 494-506, 2014.

ALTBACH, P.; KNIGHT, J. Motivations and realities. Journal of Studies in International Education, v. 11, n. 3/4, pp. 290-305, 2007.

BARTELL, M. Internationalization of universities: A university culture-based framework. Higher Education, v. 45, pp. 43-70, 2003.

BRASIL. Lei $n^{o} 13.005$, de 25 de junho de 2014 - Plano Nacional de Educação (PNE). Brasília, D.O., 2014.

BRETON, G. de. L'internationalisation à la Globalisation de l'Enseignement Supérieur. In: BRETON, G. de; LAMBERT, M. Globalisation et Universités. Nouvel Espace, nouveaux acteurs. Laval: UNESCO/Les Presses de L’Université Laval, 2003.

CAPES. Programa de Doutorado Sanduíche no Exterior (PDSE). 2015a. Disponível em: $<$ http://www.capes.gov.br/bolsas/bolsas-no-exterior/programa-de-doutorado-sanduiche-noexterior-pdse>. Acesso em: 20 jul. 2015.

. Manual de Candidatura: Programa de Doutorado Sanduíche no Exterior - PDSE. Brasília, 2015b. 
. Doutorado Sanduiche no Exterior (SWE). Ciência sem Fronteiras - CsF. 2015c.

Disponível em: <http://www.cienciasemfronteiras.gov.br/web/csf/doutorado-sanduiche>. Acesso em: 20 jul. 2015.

CHESNAIS, F. A mundialização do capital. São Paulo: Xamã, 1996.

DE WIT, H. (eds.). The Dynamics of International Student Circulation in a Global Context. Global Perspectives on Higher Education, v. 11, 2008.

GACEL-ÁVILA, J. Internacionalizacion de la Educación Superior en America Latina y el Caribe: Reflexiones y Lineamientos. Guadalajara: Organisation Universitaire Interamericaine y La Asociation Mexicana para la Educacion Internacional, 1999.

HARVEY, D. Condição pós-moderna. 18 ed. São Paulo: Edições Loyola, 2009.

. Condição pós-moderna: uma pesquisa sobre a origem da mudança cultural. 20 ed. São Paulo: Loyola, 2010.

IANNI, O. A Sociedade Global. Rio de Janeiro: Civilização Brasileira, 1992.

. Teorias da globalização. 10 ed. Rio de Janeiro: Civilização Brasileira, 2002.

KNIGHT, J. Updating the definition of internationalization. International Higher Education, v. 33, n. 3, pp. 2-3, 2003.

. Higher Education Crossing Borders. A Guide to the Implications of the General Agreement on Trade in Services (GATS) for Cross-border Education. Paris: COL/UNESCO, 2006.

LAUS, S. P. A internacionalização da educação superior: um estudo de caso da universidade federal de Santa Catarina. [Tese de doutorado]. Escola de Administração da Universidade Federal da Bahia (UFBA), Salvador, 2012.

MURPHY, M. Experiences in the internationalization of education: Strategies to siceppromote equality of opportunity at Monterrey Tech. Higher Education, v. 53, pp.s[Ep 167-208, 2007.

MURPHY-LEJEUNE, E. An experience of interculturality: student travellers abroad. In: Alred, G., Byram, M.. \& Fleming, M. Intercultural experience and education. Clevedon: Multilingual Matters, 2002.

REDDEN, E. Study abroad expo has countries clamoring for mobile students. Inside Higher Education. USA Today. Jun. 2010. Disponível em: $<$ http://www.usatoday.com/news/ education/2010-06-02-ihe-study-abroad_N.htm>. Acesso em: 23 jul. 2015.

SAVIANI, D. História das ideias pedagógicas no Brasil: Campinas: Autores Associados, 2007.

SEBASTIÁN, J. Cooperación e Internacionalización de las Universidades. Buenos Aires: Biblos, 2004. 
SILVA, C. C. dos S. Mobilidade corpórea de estudantes internacionais: as motivações dos estudantes internacionais acolhidos por instituições de educação superior localizadas em São Paulo e Belo Horizonte. [Dissertação de mestrado]. Escola Superior de Propaganda e Marketing, SP, 2013.

STRAUSS, A. L.; CORBIN, J. Basics of Qualitative Research: Grounded Theory Procedures and Techniques, Sage, 1990. 